\title{
The Chinese Salamander
}

\author{
Huang Zhujian
}

Because the salamander Megalobatrachus davidianus makes sounds like a baby crying, its common name in China is 'baby fish'. The largest amphibian now in existence, it may grow to $180 \mathrm{~cm}$ in length and weigh up to several dozen catties (1 catty $=\frac{1}{2} \mathrm{~kg}$ ); one specimen caught in Hunan Province weighed $65 \mathrm{~kg}$. It is one of three salamander species belonging to the Cryptobranchidae. The other two, Cryptobranchus japonicus in Japan and $C$. alleganiensis in the eastern United States, are similar to the Chinese species in shape and size, but the American one is much smaller.

The amphibians flourished when the earth consisted of a single continent, Pangaea, about $200 \mathrm{~m}$ years ago. At that time Cryptobranchid salamanders were more widely distributed over the northern hemisphere than now. Fossils have been found from formations of the Oligocene, Miocene, and Pliocene epochs of Europe, the Miocene of North America, the Palaeocene of east Asia, and the Oligocene of Kazakhstan. The oldest fossilised specimen unearthed so far, from the Lower Eocene in Wyoming, is between about 3 and $70 \mathrm{~m}$ years old. When Pangaea split apart into plates, these drifted further and further from one another and became separated by oceans. With changes in geography and climatic conditions, many Cryptobranchid species, like other animals, were eliminated through natural selection, leaving only the two in east Asia and one in the eastern United States.

\section{Range}

The Chinese species is the most widely distributed. It occurs in the tributaries of the Yangzi River, the Yellow River, and the middle or lower reaches of the Pearl River, its range covering 17 provinces and regions, among them Shanxi, Shaanxi, Henan, Hubei, Hunan, Anhui, Sichuan, Guizhou, Guangxi, Guangdong, and Fujian. These salamanders are usually solitary, living in fast clear mountain streams, $200-1000 \mathrm{~m}$ above sea level. They position themselves in dark, muddy rock crevices that are wide enough to allow them easy movement, facing outwards for feeding and self-defence, and remain still. The water temperature varies between $10^{\circ}$ and $18^{\circ} \mathrm{C}$. In spring and summer they are found at cave entrances and in autumn and winter deep within. In the daytime they are sluggish and slow, shunning the light, although in spring, they sometimes come out to bask in the sun. In summer and autumn they come out by night and hide by day. The adults are lazy and inactive, but temperamental; snapping at each other during the night.

\section{Breeding}

The breeding season is from June to August. They are oviparous, fertilisation occuring externally. Spawning takes place in caverns: the ova are attached to rocks in areas with a slow-moving current, the male fertilising the eggs after the female has spawned. Each female produces more than 300 of the round, bean-shaped ova, which are covered by transparent gel to form a long chain-like tube. Incubation takes about three weeks. The number of eggs is not large. The egg-count of a Megalobatrachus $100 \mathrm{~cm}$ long and weighing about $7.5 \mathrm{~kg}$ is 1500 ; at $40-80 \mathrm{~cm}$ and $0.5-3 \mathrm{~kg}$ it is $300-600$. Survival rate is very low and the young grow slowly, reaching around $200 \mathrm{~mm}$ in length and less than $100 \mathrm{~g}$ after three years.

'The baby fish sits on shore, and delights in eating what comes his way,' is a common saying among the people of Sichuan Province. To catch its prey, the 


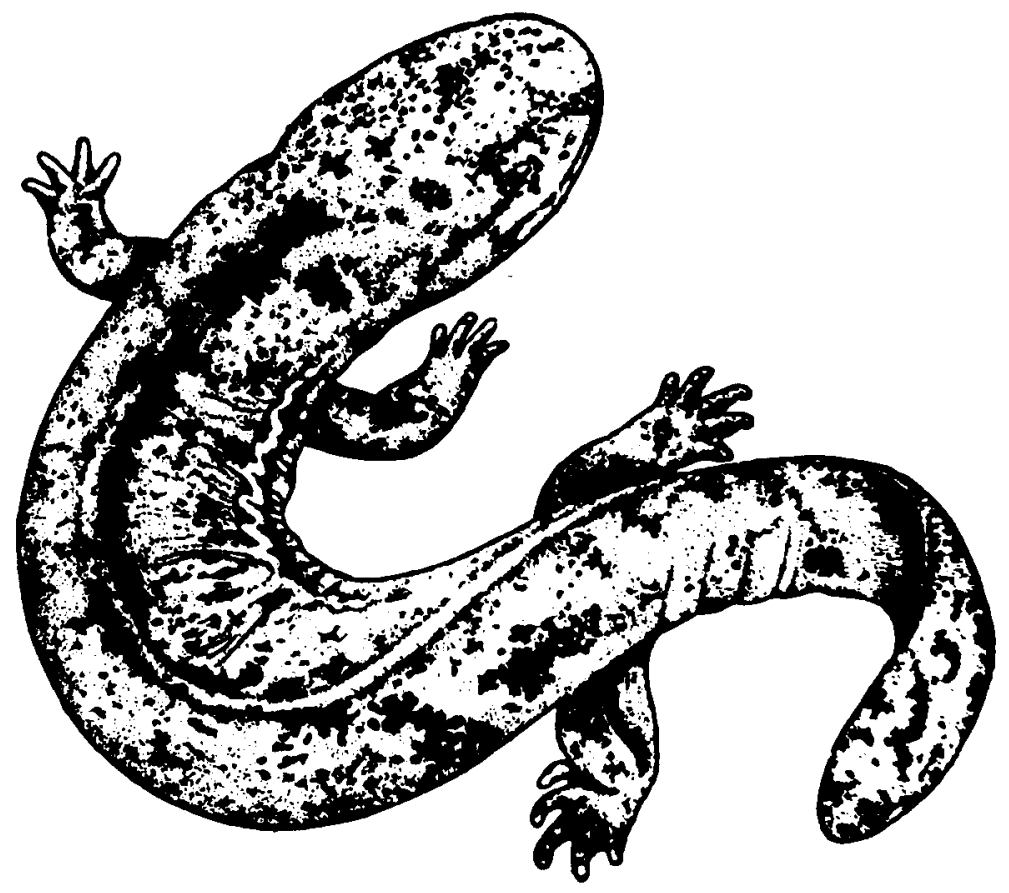

salamander hides among the rocks at night, at tacking suddenly when a suitable prey passes by and swallowing it immediately. Crabs and frogs are the main food (60-70 percent); fish, shrimp, snakes, aquatic insects, young turtles, water rats and plant residue are also eaten. The young are herbivorous, becoming carnivorous when about two years old. The salamander's metabolism is slow, but its ability to endure starvation is considerable, and even after long periods it does not lose weight. It can survive without food for a full year, but it cannot live out of water. The flesh is delicious and nourishing, and also has medicinal value.

The salamander is a protected species in China's second category. Local people and scientists agree that they should only be caught under licence from the responsible authorities, and that poison bait should be strictly forbidden. Because the

salamanders do not reach sexual maturity until they weigh at least $0.5 \mathrm{~kg}$, none under that weight should be sold, and they should be specially protected in the breeding season. In some areas, too many have been caught and numbers have declined. Campaigns to promote strict protection are needed so that breeding can resume unhindered, and in counties where conditions are appropriate, captive breeding should be encouraged.

\section{Acknowledgment}

We are most grateful to Ms Chen Ching who translated this article from the Chinese, and to Mr Tom Gorman, editor of the International Industrial Report, a Chinese language magazine published in Hong Kong, who helped. Editor.

Huang Zhujian, Department of Vertebrate Taxonomy, Institute of Zoology, Adcadema Sinica, Zhong Guan Cun, Beijing, China.

Birds: their Latin names explained, by A.F. Gotch (Blandford, £10.95), includes some 1850 out of the 8600 known bird species, mainly the better known ones. 
This RWANDA BANKNOTE, with a picture of mountain gorillas taken from the ffPS Christmas card by Bruce Pearson, is interesting evidence of the success of the Mountain Gorilla Project launched by fPS and PTES in Rwanda in 1978.

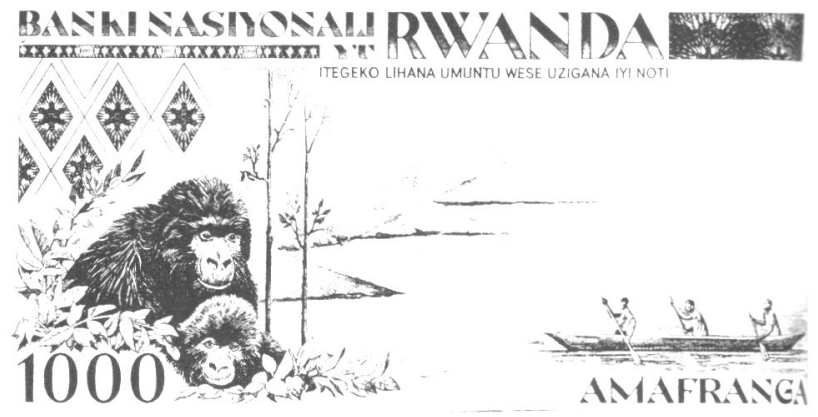

\section{Elephants and Rhinos in Africa}

There are now some 600,000 elephants left in those parts of Africa where accurate surveys have been conducted, and anything from half a million to a million in the unsurveyed elephant range. This was one of the conclusions of a meeting of elephant and rhino specialists convened by the IUCN Species Survival Commission in Zimbabwe in August 1981, jointly with WWF. The most urgent elephant conservation needs are in West Africa, where they survive only in fragmented and beleaguered populations, mainly in Liberia and the Ivory Coast. The rhino situation is much more serious, with no more than 23,000 black rhinos left in the whole of Africa and numbers still falling rapidly. Ninety per cent of Kenya's rhinos have been lost since 1970 . There are, however, nearly 3000 southern white rhinos, 2500 of them in South Africa, a remarkable recovery for a subspecies that was believed in the 1920 s to be extinct. The northern race of the white rhino, however, is now down to 700 in the wild, almost all in the southern Sudan and northern Zaire.

\section{Plan for the Scimitar-horned Oryx}

An anonymous West German donor last year gave $\$ 450,000$ for the conservation of the scimitar-horned oryx in West Africa, and WWF (mainly the UK National Appeal) added $\$ 100,000$ to this, particularly to buy vehicles for the Air Reserve. Half the money will be used to help establish another reserve in the area surveyed two years ago, and some to a survey of the region around and west of the Termit Massif as a likely area for an oryx reserve. Oryx numbers are put at between 500 and 200 , the majority in the 30,000-sq-mile Ouadi Rimé-Ouadi Achim Faunal Reserve in Chad, which is the size of Scotland, but what effect the civil war has had is not known; they could be near being exterminated. Long-term plans for these oryx include an operation very like that already under way for the Arabian oryx: taking zoo-bred ory $x$ from Britain and the USA to a breeding compound in the African reserve from which they could be released.

The Pretoria National Zoological Gardens, which also runs a wildlife sanctuary and breeding reserve in the western Transvaal, has bred 61 scimitar-horned oryx in 13 years.

\section{Fighting the Poachers}

The Save the Rhino Trust, a new voluntary organisation in Zambia, is helping the National Parks and Wildlife Department to grapple with the poaching in the Luangwa, Luano and Zambesi valleys. The Trust's two mobile units, in vehicles supplied by WWF, are called out when the regular guards spot poachers, and have had considerable success both in reducing poaching - not long ago the estimate was one rhino poached every day - and catching some of the gangs. One gang recently shot 18 elephants with automatic rifles. The Trust's hon. rangers operate on the roads outside the reserves, setting up road blocks to intercept people illegally carrying tusks and other wildlife products.

\section{Correction}

In Oryx 16, 1, page 14, it was wrongly stated that the Botswana Government had destroyed all stocks of rhino horn. This should have read Bophutatswana. This newly independent South African republic is giving high priority to conservation, and the $600-\mathrm{sq}-\mathrm{km}$ Pilanesberg Game Reserve is being upgraded to a national park. 